\title{
Rubber composite fibers containing silver nanoparticles prepared by electrospinning and in-situ chemical crosslinking
}

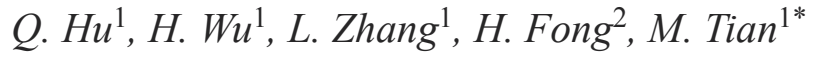 \\ ${ }^{1}$ State Key Laboratory of Organic-Inorganic Composites, Beijing University of Chemical Technology, Chao-Yang \\ District, 100029 Beijing, China \\ ${ }^{2}$ Department of Chemistry, South Dakota School of Mines and Technology, Rapid City, 57701 South Dakota, USA
}

\begin{abstract}
Rubber composite fibers containing silver nanoparticles with high morphological stability were prepared through combination of electrospinning and in-situ chemical crosslinking. The composite fibers included those of Ag/polybutadiene rubber (BR), Ag/polyisobutylene-isoprene rubber (IIR), and Ag/silicon rubber ( $\mathrm{SiR}$ ). During the study, Ag nanoparticles (Ag NPs) were first generated through reducing the $\mathrm{Ag}^{+}$ions in rubber/N,N-dimethyformamide/tetrahydrofuran solutions upon ultraviolet-irradiation; subsequently, rubber composite fibers with uniform diameters from hundreds of nanometers to several micrometers were made by electrospinning the above solutions. The electrospinning was carried out with in-situ chemical crosslinking. The results indicated that chemical crosslinking during (and shortly after) electrospinning was able to improve substantially the morphological stability of rubber fibers. As indicated by the results acquired from UV absorption spectroscopy, X-ray photoelectron spectroscopy and transmission electron microscope, Ag nanoparticles with sizes of $10 \sim 20 \mathrm{~nm}$ were uniformly dispersed in rubber fibers. It was believed that, in addition to the protection of polyvinyl pyrrolidone, a rapid solvent evaporation and limited motion space for a very fine fiber during electrospinning could prevent $/ \mathrm{miti}$ gate the aggregation of Ag NPs, resulting in a very uniform dispersion. The electrospun Ag NPs/BR composite fibers made of the solution containing very low loading amount ( $3 \mathrm{wt} \%$ ) of $\mathrm{AgNO}_{3}$ demonstrated strong antimicrobial activity.
\end{abstract}

Keywords: rubber, electrospinning, composite fiber, silver nanoparticles, in-situ crosslinking

\section{Introduction}

Recently, the incorporation of metal nanoparticles into polymer nanofibers has attracted growing attentions, because this type of nanocomposite nanofibers would combine the unique properties of metal nanoparticles (e.g., magnetic, optical, electronic, catalytic, and antimicrobial properties) with the outstanding characteristics of polymer nanofibers (e.g., the high specific surface area and high interpenetrating capacity in other materials, etc.) [1-8]. Among various metal nanoparticles, silver nanoparticles (Ag NPs) have been of particular interest due to their catalytic property, high electrical conductivity, and antimicrobial activity etc [9-12]. Ag NPs have been synthesized in many different ways including chemical reduction, X-ray irradiation, refluxing and heating methods and bio-reduction [13-15]. Nevertheless, Ag NPs have the tendency to form agglomerates; and thus it has been a technological challenge how to disperse them uniformly in polymeric matrices.

To the best of our knowledge, the polymers that have been electrospun into nanofibers with Ag NPs are mostly thermoplastics such as polyvinyl pyrroli-

\footnotetext{
${ }^{*}$ Corresponding author, e-mail: tian71402@126.com

(c) BME-PT
} 
done (PVP), polyvinyl acetate (PVA), polyacrylonitrile (PAN), etc. [17-20]; whereas electrospun Ag $\mathrm{NPs} /$ rubber composite fibers have rarely been reported [21]. This is probably due to the reason that rubbers have glass transition temperatures lower than room temperature, and the excellent elasticity might hinder the formation of fibers during electrospinning. Additionally, the macromolecular chains of rubbers are able to move (i.e., rearrange their conformations) in electrospun fibers, such a movement and/or relaxation occurs when the stretching force no longer exists, and is driven by entropy increase. The results often include the breakage and/or conglutination of fibers with prolonging the storage time [22, 23].

It is expected that the rubber fibers would be important for applications in need of large deformation and elasticity. For example, silicon rubber ( $\mathrm{SiR}$ ) and isobutylene-isoprene rubber (IIR) exhibit excellent biocompatibility and low gas permeability in addition to superior elasticity. Herein, three kinds of rubbers including butadiene rubber (BR), IIR, and $\mathrm{SiR}$ were studied. N,N-dimethyformamide (DMF) was selected as a co-solvent for three rubbers, as well as the reducing agent for converting $\mathrm{Ag}^{+}$ions into Ag NPs. The resulting solutions containing Ag NPs were directly used for electrospinning. To improve the morphological stability of Ag NPs/rubber composite fibers, the in-situ chemical crosslinking was conducted during and shortly after electrospinning; camphorquinone (CQ) was used as the
UV-photo initiator for BR and IIR, whereas a curing agent containing the catalyst of platinum was used for SiR. The addition of PVP into the $\mathrm{Ag}^{+} / \mathrm{rub}-$ ber solutions aimed to prevent the Ag NPs from agglomeration, as well as to promote the reduction of $\mathrm{Ag}^{+}$ions into $\mathrm{Ag} \mathrm{NPs}$.

\section{Experimental part}

\subsection{The preparation of Ag NPs/rubber composite fibers}

The preparation process is shown in the Figure 1. $\mathrm{AgNO}_{3}$ and PVP (M=1 300 000) (mass ratio of $\mathrm{AgNO}_{3} / \mathrm{PVP}$ being 1/1, $1 \mathrm{wt} \%$ to rubber), supplied by the Beijing Hua-Teng Chemical Reagent Co. (Beijing, China) and Alfa Co. (America), respectively, were dissolved in N,N-dimethyformamide (DMF) and the solution was then added to the solvent of tetrahydrofuran (THF) (mass ratio of THF/ DMF being 4/1) drop by drop. Polybutadiene rubber (BR), supplied by the Beijing Yan-Shan Petrochemical Co. (Beijing, China), was first kneaded on a two-roll mill at $\sim 25^{\circ} \mathrm{C}$ for $10 \mathrm{~min}$. Subsequently, $8 \mathrm{wt} \%$ of BR was dissolved in the above THF/DMF solutions. The BR solution was then exposed to ultraviolet irradiation for about $1 \mathrm{~h}$ for the reduction of $\mathrm{Ag}^{+}$ions into $\mathrm{Ag}$ NPs. Prior to electrospinning, camphorquinone (CQ) was added into the solutions for in-situ photo-crosslinking. Finally, the solutions were filled in $30 \mathrm{~mL}$ plastic syringes having bluntend stainless-steel needles with inside diameter of $0.30 \mathrm{~mm}$. The electrospinning setup included an

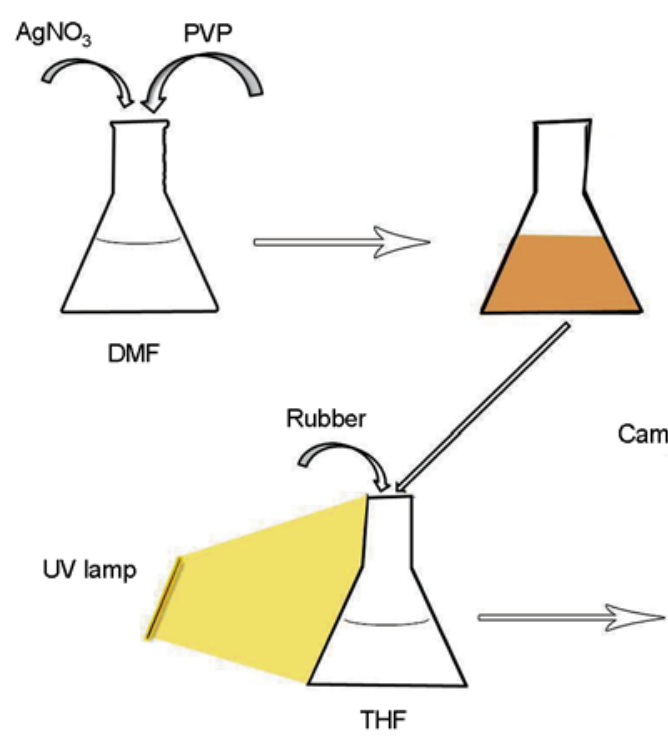

Rubber solutions

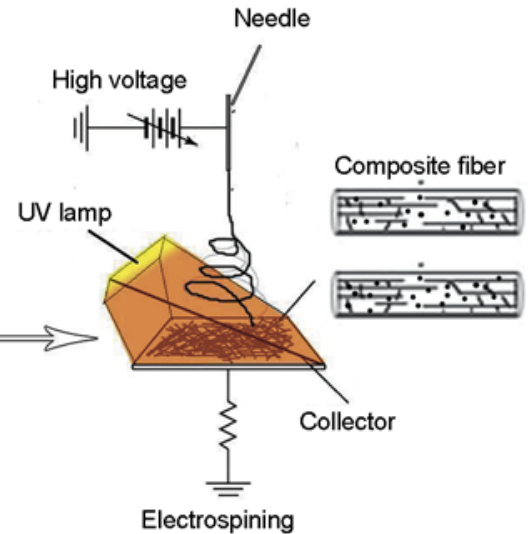

Figure 1. Schematic diagram of experimental process 
ES30P high voltage power supply, purchased from the Gamma High Voltage Research, Inc. (Ormond Beach, USA), and a fiber collector of electrically grounded metal plate covered with aluminum foil. The collector was placed at $15 \sim 20 \mathrm{~cm}$ below the needle and exposed to a $100 \mathrm{~W}$ halogen lamp. During electrospinning, a positive high voltage of 10 $20 \mathrm{kV}$ was applied to the needle; and the solution feed-rate of $1.5 \mathrm{~mL} / \mathrm{h}$ was maintained using a syringe pump. Isobutylene-isoprene rubber (IIR), also supplied by the Beijing Yan-Shan Petrochemical Co., had a similar process of electrospinning as BR. Silicon rubber (SiR), supplied by the Dow Corning Co. (USA), also had a similar process of electrospinning as BR except that a curing agent containing the catalyst of platinum (PL-10A: 4\%, PL-10B: 6\%, SiR: $20 \%$ ) was chosen for in-situ chemical crosslinking.

\subsection{Characterization of Ag NPs/rubber composite fibers}

For morphological characterizations, electrospun $\mathrm{BR}$, IIR and SiR fibers were collected with glass slides on the metal plate; and the fibers were examined with XSJ-2 optical microscope purchased from the Chongqing Optical Instrument Co. (Chongqing, China). UV absorption spectrum of the $\mathrm{Ag} / \mathrm{BR}$ fiber mat in the $300-700 \mathrm{~nm}$ region was obtained by the UV-3150 spectrophotometer purchased from the Shimadzu Co. (Shimadzu, Japan) and a piece of aluminum foil covering with $\mathrm{Ag} / \mathrm{BR}$ fiber mat was used for UV measurement. A piece of $\mathrm{Ag} / \mathrm{BR}$ fiber mat was placed on a copper grid to observe the shape and distribution of silver nanoparticles in electrospun Ag NPs/BR composite fiber by H-800 transmission electron microscopy purchased from Hitachi Co. (Japan). XPS measurements were carried out on an ESCALAB 250 purchased from Thermo Electron Corporation (USA) with an $\mathrm{Al} \mathrm{K}_{\alpha}$ $\mathrm{X}$-ray source at $1486.6 \mathrm{eV}$ photons. The core-level signals were obtained at a photoelectron take off angle of $45^{\circ}$ (with respect to the sample surface). The $\mathrm{X}$-ray source was run at a reduced power of $150 \mathrm{~W}$.

\subsection{Antimicrobial activity test of $\mathrm{Ag} / \mathrm{BR}$ composite fibers}

The antimicrobial activity of BR composite fibers with and without Ag NPs was tested against Gramnegative Escherichia coli (E.coli, ATCC 25922) according to Chinese national testing standard of antimicrobial activity in the 'Technical Standard For Disinfection' (2002). For antimicrobial activity characterization, the randomly overlaid fiber mats were obtained by collecting $\sim 1 \mathrm{mg}$ of BR fibers (with and without Ag NPs) with glass slides ( $25 \mathrm{~mm} \times$ $25 \mathrm{~mm}$ ). The agar plates containing test samples and the control (BR fibers without Ag NPs) were incubated at $37^{\circ} \mathrm{C}$ for $24 \mathrm{~h}$. The reductions of bacteria were calculated according to the equation of 'Reduction [\%] $=(B-A) / B \cdot 100$ ', where $A$ and $B$ are the surviving cells (colony forming unit. $\mathrm{mL}^{-1}$ ) for the plates containing test samples and the control, respectively.

\section{Results and discussion}

\subsection{In-situ formation of silver nanoparticles}

In this study, DMF was used as a reducing agent for converting $\mathrm{Ag}^{+}$ions into Ag NPs. During the reactions performed at room temperature, the following reaction according to Equation (1) would occur:

$$
\begin{aligned}
& \mathrm{HCONMe}_{2}+2 \mathrm{Ag}^{+}+\mathrm{H}_{2} \mathrm{O} \rightarrow \\
& 2 \mathrm{Ag}^{0}+\mathrm{Me}_{2} \mathrm{NCOOH}+2 \mathrm{H}^{+}
\end{aligned}
$$

However, the reaction would proceed at a low rate when performed at room temperature. In this study, we obtained the quick in-situ synthesis of Ag NPs in the rubber solution with further ultraviolet irradiation. The following reaction given by Equation (2) took place during the ultraviolet irradiation process:

$$
\begin{aligned}
\mathrm{Ag}^{+}+\mathrm{NO}_{3-} & \stackrel{\mathrm{hv}}{\rightarrow} \mathrm{Ag}^{0}+\mathrm{NO}_{2}+\frac{1}{2} \mathrm{O}_{2} \\
n \mathrm{Ag}_{0} & \rightarrow(\mathrm{Ag})_{\mathrm{n}}
\end{aligned}
$$

The reduction of $\mathrm{Ag}^{+}$ions by DMF could be monitored from the color evolution of the solution. Visual observation showed that, as the reaction proceeded, the color shifted from light yellow, bright yellow, to dark brown after 10, 30, $60 \mathrm{~min}$, respectively, as depicted in Figure 2. In this study, we also introduced PVP into the rubber solution in order to protect the Ag NPs from agglomeration; so that they could be uniformly dispersed in electrospun composite fibers. The fast evaporation of solvent during the process of electrospinning also prevented from Ag NPs self-aggregation in the rubber fibers because of very limited space. The absorption spectrum of $\mathrm{Ag} /$ rubber composite fiber mat is shown in Figure 3 and it can be seen that an absorption band with a sharp maximum at about $424 \mathrm{~nm}$ arises. Small metal- 


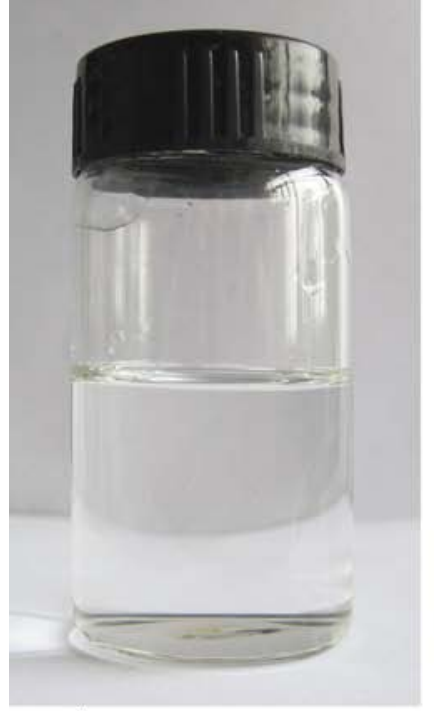

a)

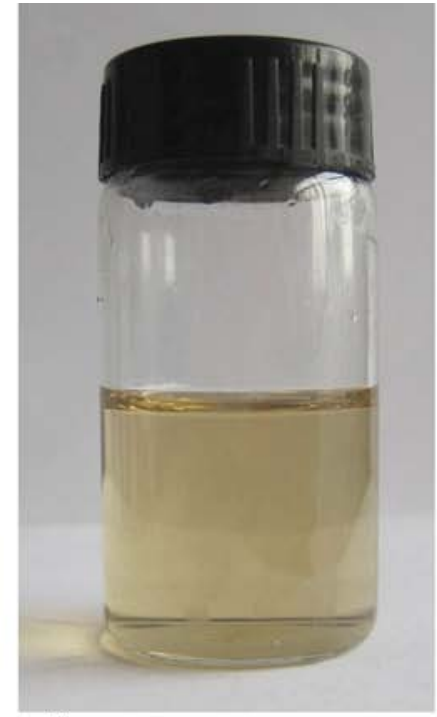

b)

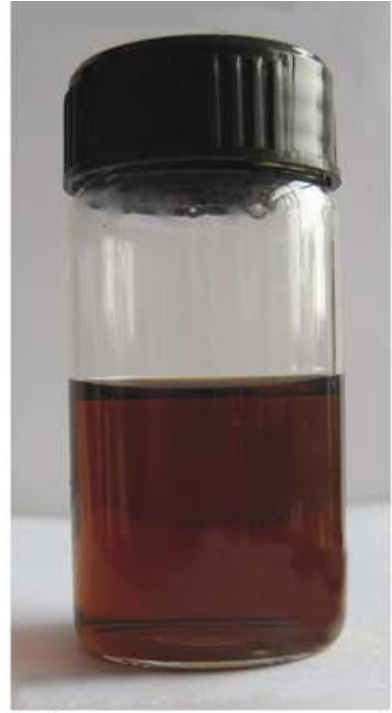

c)

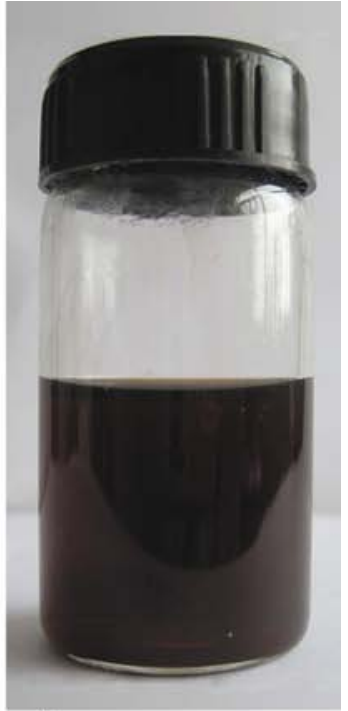

d)

Figure 2. Color evolution of $\mathrm{AgNO}_{3} / \mathrm{DMF}$ solution with ultraviolet irradiation for varied time periods of (a) 0 min, (b) $10 \mathrm{~min}$, (c) $30 \mathrm{~min}$, and (d) $60 \mathrm{~min}$

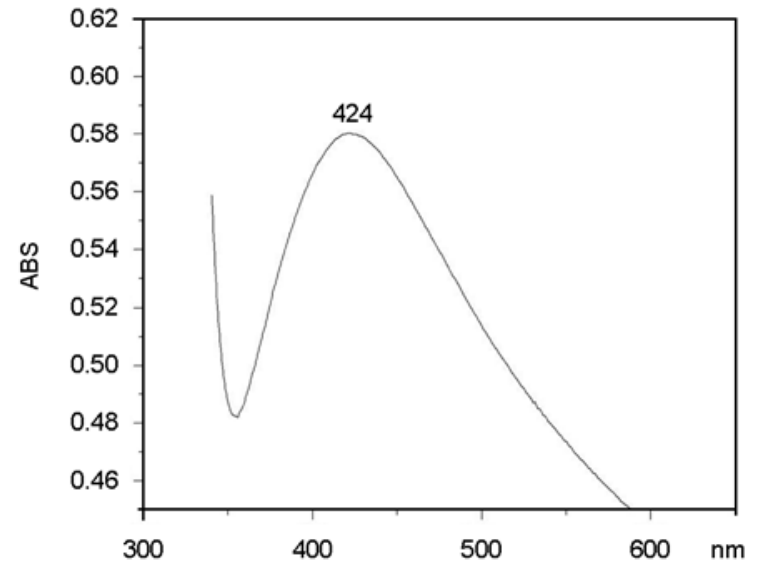

Figure 3. UV spectrum of Ag NPs/BR composite fiber mat prepared from the solution containing $3 \mathrm{wt} \%$ $\mathrm{AgNO}_{3}$

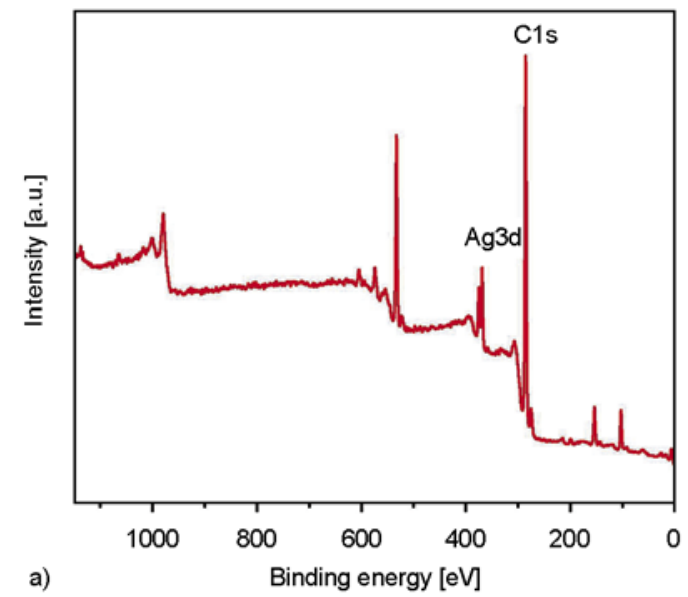

lic particles exhibit a high optical absorbance due to the existence of discrete energy levels of electron and particularly of specific states. Ag NPs with diameters below $5 \mathrm{~nm}$ have a rather high absorbance band with a maximum at about $400 \mathrm{~nm}$ and with diameters of $\sim 10 \mathrm{~nm}$ exhibit absorption bands at $410 \sim$ $450 \mathrm{~nm}$ depending on their chemical environment. Based on the maximal absorbance at $424 \mathrm{~nm}$ caused by Ag/rubber fiber mat, small spherical particles of silver with diameters of $10 \mathrm{~nm}$ or less were formed. Figure 4 showed the spectrum in the $\mathrm{Ag} 3 \mathrm{~d}$ region of the Ag/rubber composite fibers. It was evident from the spectrum that two peaks occurred at 368.1 and $374.1 \mathrm{eV}$, corresponding to $\mathrm{Ag} 3 \mathrm{~d} 1 / 2$ and $3 \mathrm{~d} 3 / 2$ binding energies, respectively. The result further confirmed the existence of $\operatorname{Ag}(0)$ in the $\mathrm{Ag} / \mathrm{rubber}$ composite fiber mat [24, 25].

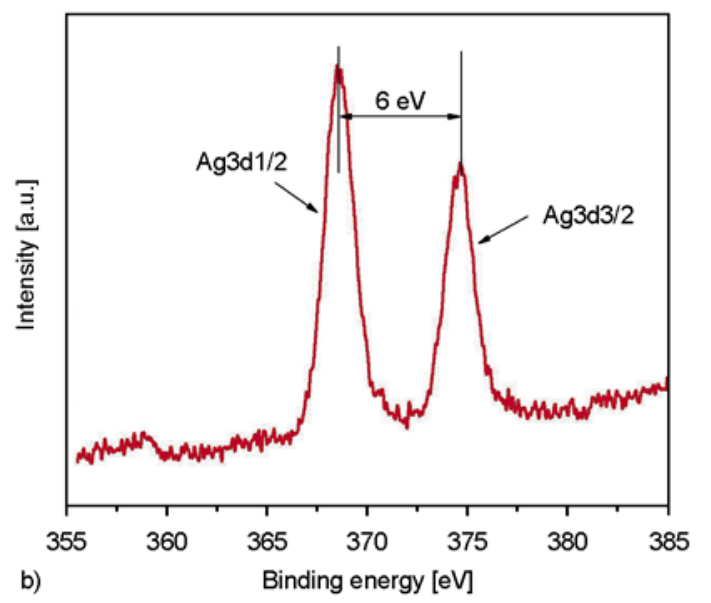

Figure 4. Wide-scan and Ag3d XPS spectra for electrospun Ag NPs/BR composite fiber mat prepared from the solution containing $3 \mathrm{wt} \% \mathrm{AgNO}_{3}$ : (a) wide-scan, (b) $\mathrm{Ag} 3 \mathrm{~d}$ 


\subsection{Morphology of Ag/rubber composite fibers}

To investigate the morphological stability of electrospun rubber fibers (here only taking BR as an example), the prepared fibers were stored under ambient condition or immersed in THF (a good solvent for $\mathrm{BR}$ ) (with temperature being $\sim 25^{\circ} \mathrm{C}$ and relative humidity being $\sim 50 \%$ ) for a period of time $\sim 20 \mathrm{~h}$. As shown in Figure 5, the Ag/BR composite fibers immediately after electrospinning possessed the cylindrical morphology, while the morphology was partially lost after storage under ambient condition, further prolonging the storage time led to the conglutination and/or breakage of the fibers for $20 \mathrm{~h}$ as seen in Figure 5d. When soaked in THF for $20 \mathrm{~h}$, the electrospun $\mathrm{Ag} / \mathrm{BR}$ composite fiber were completely dissolved (Figure 5e). Upon a series of experiments, the optimal mass ratio of CQ in $\mathrm{BR}$ was identified at $5 \%$, the crosslinked $\mathrm{Ag} / \mathrm{BR}$ composite fibers still well-retained their morphology even soaked in THF for $20 \mathrm{~h}$; the fibers were merely swollen to a certain degree (Figure $5 \mathrm{f}$ ). It could be concluded that in-situ chemical crosslinking during and shortly after electrospinning was able to substantially improve the morphological stability of electrospun BR fibers. During electrospinning, macromolecular chains in the spinning solution are stretched and/or aligned by electric force; simultaneously, the solvent in the electrospinning jet evaporates rapidly. Unlike thermoplastics, BR has the glass transition temperature $\left(T_{\mathrm{g}}\right)$ of about $-105^{\circ} \mathrm{C}$. The macro- molecular movement and/or relaxation occur when the stretching force no longer exists, so the BR fibers will collapse, conglutinate, even break. In this study, the method of in-situ chemical crosslinking combined with electrospinning was established to obtain electrospun rubber composite fibers with stable morphology. The chemically cross-linked network might restrain the motion of rubber chains and extend molecular relaxation time [26-28], so the substantially improved morphological stability of electrospun rubber composite fibers was achieved. We also prepared morphologically stable electrospun Ag NPs/IIR and Ag NPs/SiR composite fibers successfully through the combination of electrospinning and in-situ chemical crosslinking. Similar to BR, prior to electrospinning, CQ for IIR and platinum-containing curing agent for $\mathrm{SiR}$ were added into the solutions for in-situ chemical crosslinking. The TEM images in Figure 6 showed the morphologies of crosslinked $\mathrm{Ag} \mathrm{NPs} / \mathrm{IIR}$ and $\mathrm{Ag} \mathrm{NPs} / \mathrm{SiR}$ composite fibers made of 15 min kneaded IIR and as-received SiR. The chemically crosslinked Ag NPs/SiR composite fibers possessed approximately cylindrical morphology with uniform diameters of $1 \sim 2 \mu \mathrm{m}$. The diameters of Ag NPs/BR and Ag NPs/IIR composite fibers were $\sim 400 \mathrm{~nm}$, which was smaller than the diameters of Ag NPs/SiR composite fiber because $\mathrm{SiR}$ is the most elastic rubber. The typical TEM images of the rubber composite fibers containing Ag NPs are shown in Figure 6.

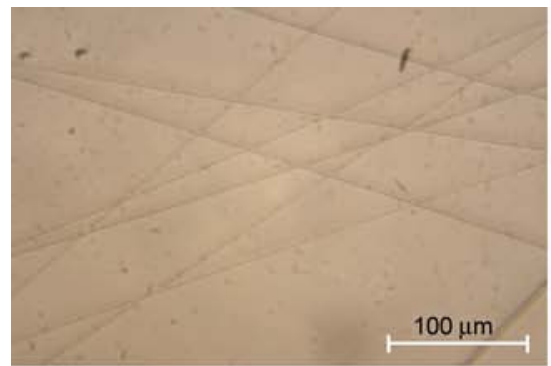

a)

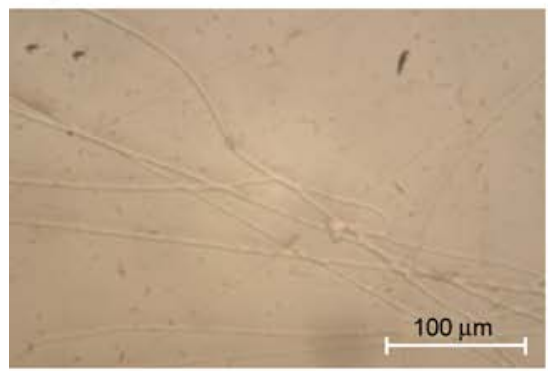

d)

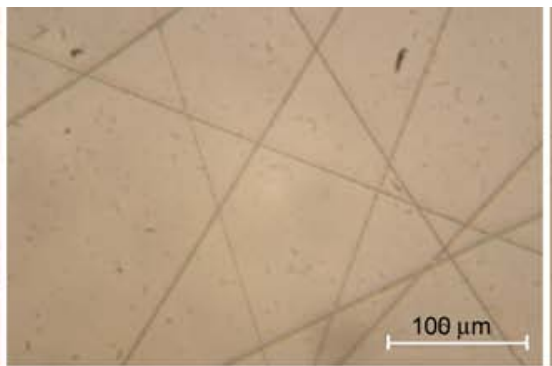

b)

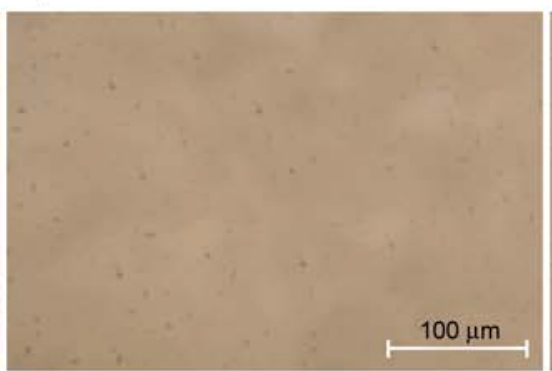

e)

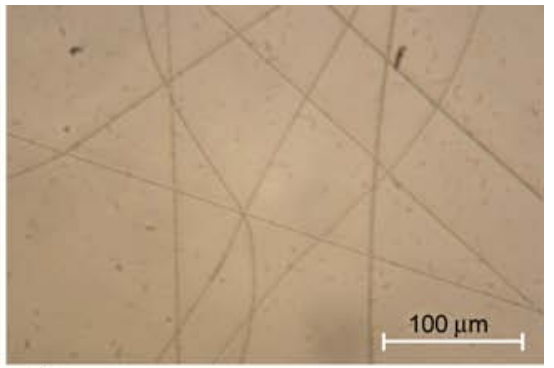

c)

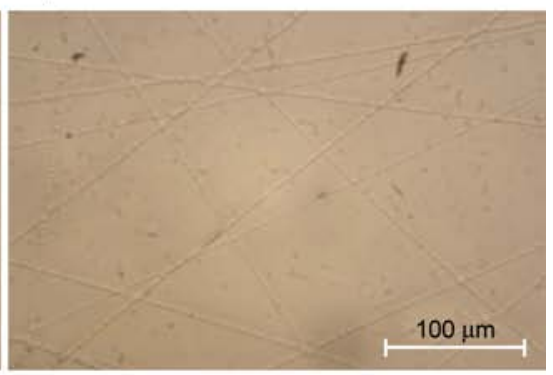

f)

Figure 5. Optical microscope images showing the morphological variations of electrospun Ag NPs/BR composite fibers (un-crosslinked: a, b, d, e; crosslinked: c, f; immediately after electrospinning: a-c; kept for $20 \mathrm{~h}$ under ambient condition: $\mathrm{d}$; and immersion in THF for $20 \mathrm{~h}$ : e, f) 

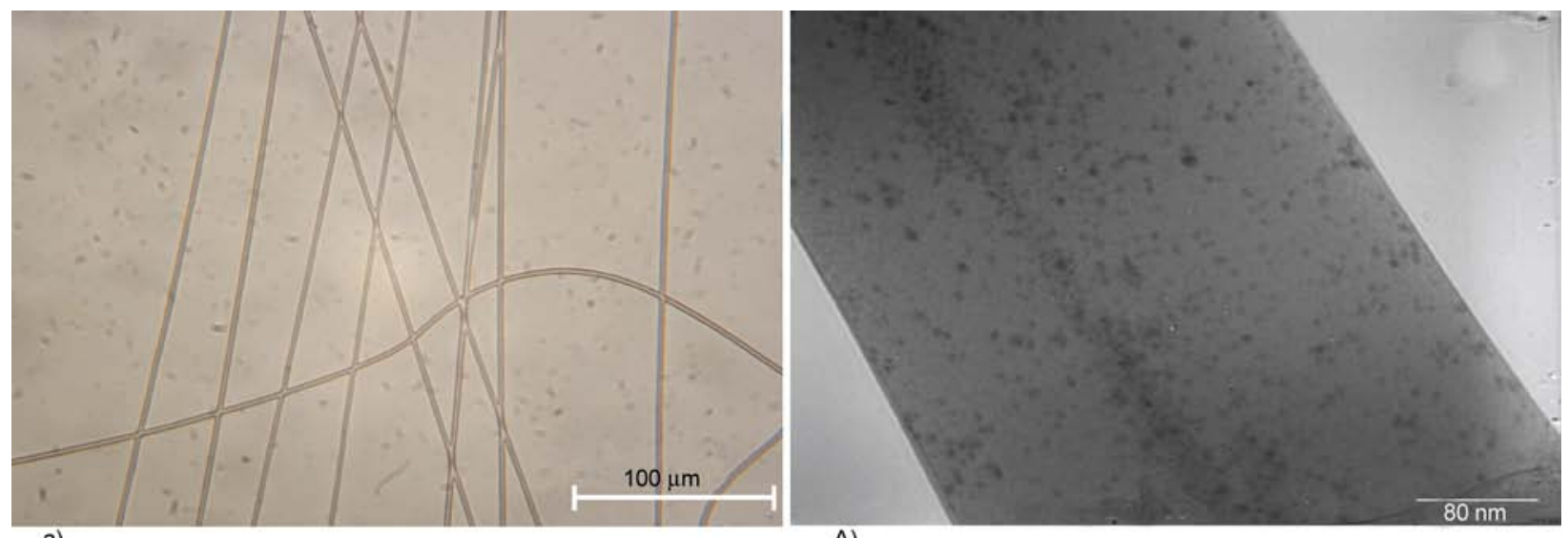

a)
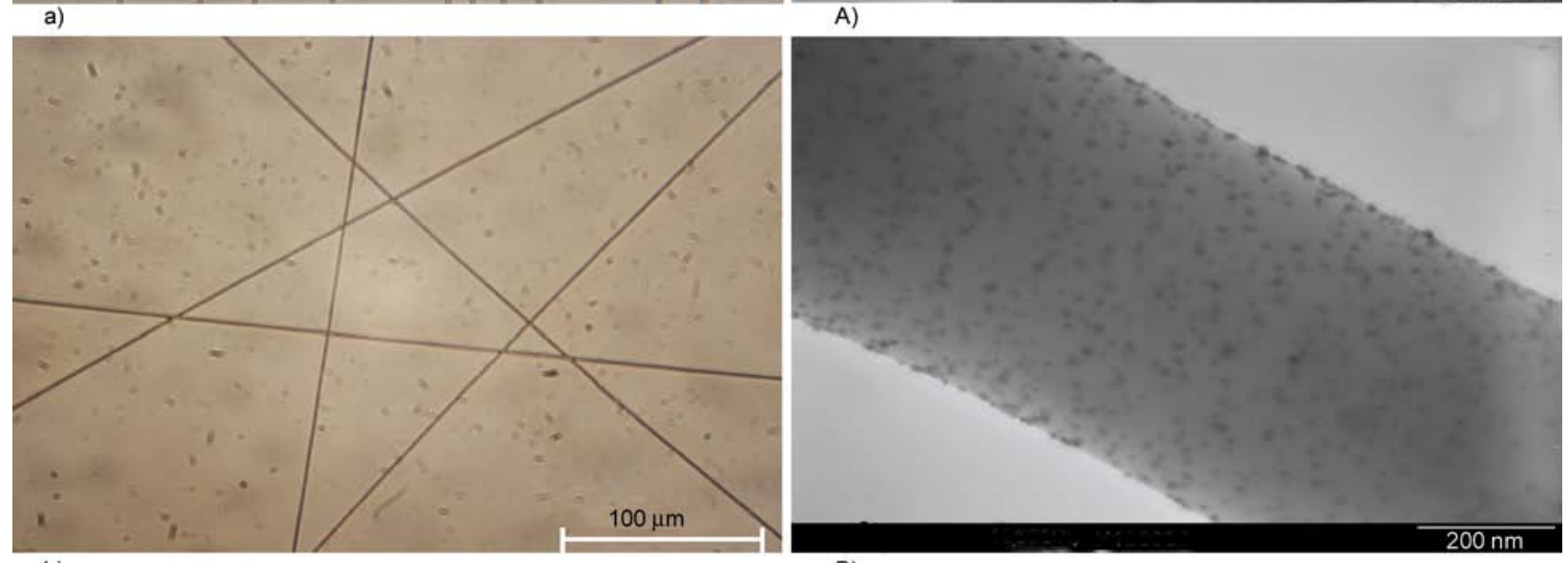

B)
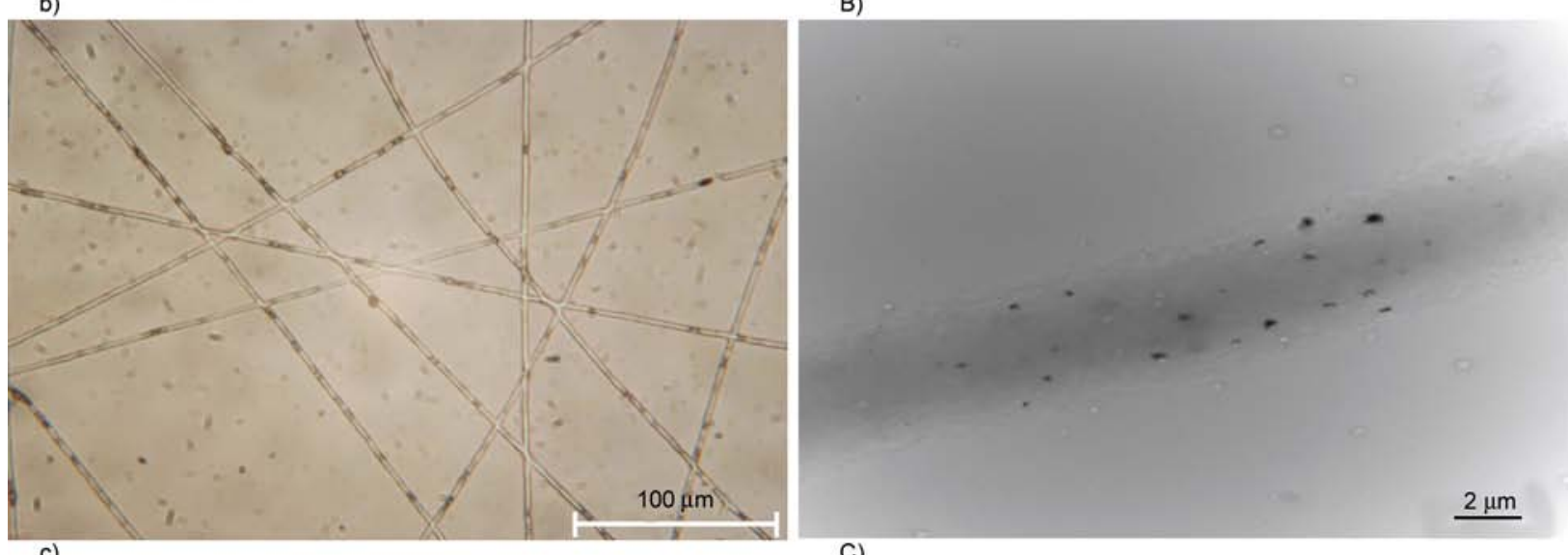

c)

C)

Figure 6. Optical microscope images $(\mathrm{a}-\mathrm{c})$ and TEM images $(\mathrm{A}-\mathrm{C})$ of Ag NPs-containing composite fibers of rubbers including BR (a, A), IIR (b, B), and $\operatorname{SiR}(\mathrm{c}, \mathrm{C})$

The Ag NPs were uniformly dispersed/distributed in the composite fibers and the average diameter of Ag NPs was about 10 20 nm, which was consistent with the results acquired from UV absorption spectra. In this study, we used DMF as a reducing agent for converting $\mathrm{Ag}^{+}$ions into $\mathrm{Ag}$ NPs at room temperature and UV-irradiation to greatly improve the reaction speed. Different from traditional chemical reduction in solution compounding, besides the protection of PVP, a rapid solvent evaporation and limited motion space in a very fine fiber during electrospinning could considerably mitigate the agglomeration of the Ag NPs, resulting in a very uniform dispersion and the narrow particle-size distribution as shown in Figure 6.

\subsection{Antimicrobial performance of Ag NPs/rubber composite fibers}

It is likely that the nanoscale sizes of Ag NPs will allow the increase of contact surface with microorganisms, leading to an enhanced antimicrobial performance. In this study, to evaluate the antimicro- 


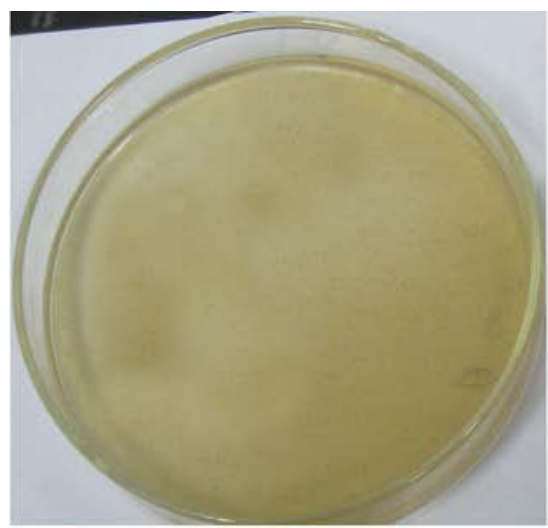

a)

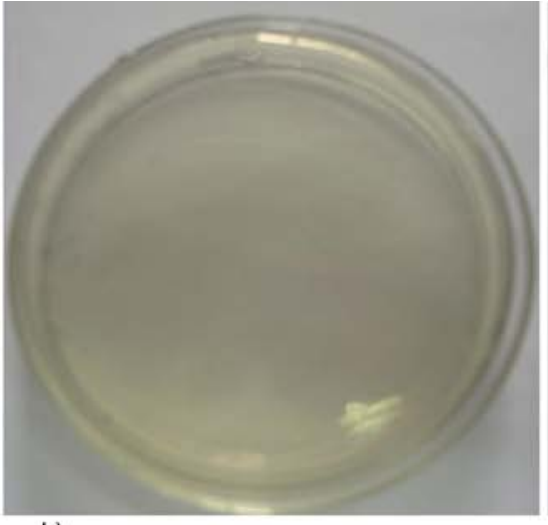

b)

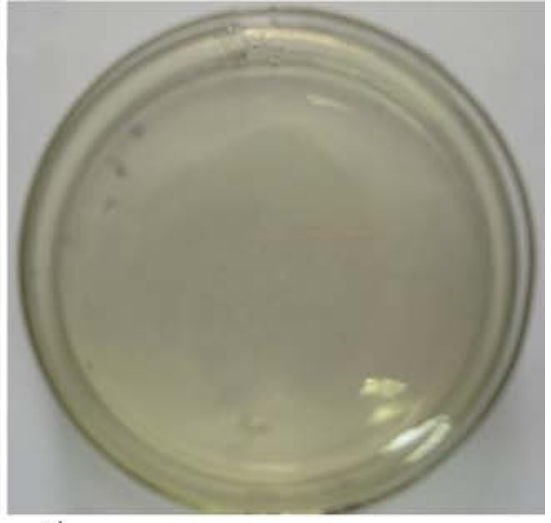

c)

Figure 7. Antibacterial activity of $\mathrm{Ag} / \mathrm{BR}$ composite fiber mats electrospun from the solutions with different $\mathrm{AgNO}_{3}$ concentrations of (a) $0 \mathrm{wt} \%$ (b) $3 \mathrm{wt} \%$ (c) $5 \mathrm{wt} \%$ against Gram-negative Escherichia coli (E. coli, ATCC 25922)

bial activity of $\mathrm{Ag} \mathrm{NPs} / \mathrm{BR}$ composite fibers, the fiber mats were tested against E. coli according to the nonwoven fabric attachment method; and the results are shown in Figure 7. Bacteria reductions for the BR fiber mats electrospun from the solutions with the original concentration of $\mathrm{AgNO}_{3}$ being 3 and $5 \mathrm{wt} \%$ were $99.9 \%$ after incubation. It is noteworthy that, if the conversion from $\mathrm{Ag}^{+}$ions to $\mathrm{Ag}$ NPs could be $100 \%$, the corresponding Ag NP concentrations in the above fiber mats would be $\sim 1.9$ and $3.2 \mathrm{wt} \%$, respectively. This indicated that a small amount of Ag NPs in the composite fibers could introduce very strong antimicrobial activity.

\section{Conclusions}

The rubber (i.e., BR, IIR, and $\mathrm{SiR}$ ) composite fibers containing Ag NPs with high morphological stability were prepared through combination of electrospinning and in-situ chemical crosslinking. The crosslinked composite fibers could well retain their morphologies whether upon prolonged storage under ambient condition or even upon immersion in THF (a good solvent for BR, IIR, and SiR). The results from UV absorption spectroscopy and TEM revealed that Ag NPs with theaverage size of 10 20 nm were dispersed uniformly in the electrospun fibers. The results from XPS further confirmed the existence of $\operatorname{Ag}(0)$ in the composite fiber mats. This study also demonstrated that the rubber composite fibers containing a very amount of Ag NPs possessed strong antimicrobial activity.

\section{Acknowledgements}

This research was supported by the National Natural Science Foundation in China (Grant Number: 50873008); the authors would also acknowledge the Chang-Jiang Scholar program of the Ministry of Education in China (Grant Number: IRT0807).

\section{References}

[1] Li D., McCann J. T., Gratt M., Xia Y.: Photocatalytic deposition of gold nanoparticles on electrospun nanofibers of titania. Chemical Physics Letters, 394, 387391 (2004). DOI: $10.1016 /$ j.cplett.2004.07.044

[2] Wang M., Singh H., Hatton T. A., Rutledge G. C.: Field-responsive superparamagnetic composite nanofibers by electrospinning. Polymer, 45, 5505-5514 (2004).

DOI: $10.1016 /$ j.polymer.2004.06.013

[3] Demir M. M., Gulgun M. A., Menceloglu Y. Z., Erman B., Abramchuk S. S., Makhaeva E. E., Khokhlov A. R., Matveeva V. G., Sulman M. G.: Palladium nanoparticles by electrospinning from poly(acrylonitrile-coacrylic acid) $-\mathrm{PdCl}_{2}$ solutions. Relations between preparation conditions, particle size, and catalytic activity. Macromolecules, 37, 1787-1792 (2004).

DOI: $10.1021 / \mathrm{ma} 035163 \mathrm{x}$

[4] Kedem S., Schmidt J., Paz Y., Cohen Y.: Composite polymer nanofibers with carbon nanotubes and titanium dioxide particles. Langmuir, 21, 5600-5604 (2005). DOI: $10.1021 / 1 \mathrm{a} 0502443$

[5] Lu X., Zhao Y., Wang C., Wei Y.: Fabrication of CdS nanorods in PVP fiber matrices by electrospinning. Macromolecular Rapid Communications, 26, 13251329 (2005). DOI: $10.1002 /$ marc. 200500300

[6] Zhu J., Wei S., Rutman D., Haldolaarachchige N., Young D. P., Guo Z.: Magnetic polyacrylonitrile-Fe@FeO nanocomposite fibers - Electrospinning, stabilization and carbonization. Polymer, 52, 2947-2955 (2011).

DOI: $10.1016 /$ j.polymer.2011.04.034 
[7] Zhu J., Wei S., Patil R., Rutman D., Kucknoor A. S., Wang A., Guo Z.: Ionic liquid assisted electrospinning of quantum dots/elastomer composite nanofibers. Polymer, 52, 1954-1962 (2011).

DOI: $10.1016 /$ j.polymer.2011.02.051

[8] Zhu J., Wei S., Chen X., Karki A. B., Rutman D., Young D. P., Guo Z.: Electrospun polyimide nanocomposite fibers reinforced with core-shell $\mathrm{Fe}-\mathrm{FeO}$ nanoparticles. The Journal of Physical Chemistry C, 114, 8844-8850 (2010).

DOI: $10.1021 / j p 1020033$

[9] Sondi I., Salopek-Sondi B.: Silver nanoparticles as antimicrobial agent: A case study on E. coli as a model for Gram-negative bacteria. Journal of Colloid Interfaces Science, 275, 177-182 (2004).

DOI: $10.1016 /$ j.jcis.2004.02.012

[10] Balogh L., Swanson D. R., Tomalia D. A., Hagnauer G. L., McManus A. T.: Dendrimer-silver complexes and nanocomposites as antimicrobial agents. Nano Letters, 1, 18-21 (2000).

DOI: $10.1021 / \mathrm{nl} 005502 \mathrm{p}$

[11] Dai J., Bruening M. L.: Catalytic nanoparticles formed by reduction of metal ions in multilayered polyelectrolyte films. Nano Letters, 2, 497-501 (2002).

DOI: 10.1021/n10255471

[12] Jin W-J., Lee H. K., Jeong E. H., Park W. H., Youk J. H.: Preparation of polymer nanofibers containing silver nanoparticles by using poly( $N$-vinylpyrrolidone $)$. Macromolecular Rapid Communications, 26, $1903-$ 1907 (2005).

DOI: $10.1002 /$ marc. 200500569

[13] Hong K. H.: Preparation and properties of electrospun poly(vinyl alcohol)/silver fiber web as wound dressings. Polymer Engineering and Science, 47, 43-49 (2007). DOI: 10.1002/pen.20660

[14] Huang H., Yuan Q., Yang X.: Preparation and characterization of metal-chitosan nanocomposites. Colloids and Surfaces B: Biointerfaces, 39, 31-37 (2004).

DOI: $10.1016 /$ j.colsurfb.2004.08.014

[15] Murugadoss A., Chattopadhyay A.: A ‘green' chitosansilver nanoparticle composite as a heterogeneous as well as micro-heterogeneous catalyst. Nanotechnology, 19, 015603/1-015603/9 (2008).

DOI: $10.1088 / 0957-4484 / 19 / 01 / 015603$

[16] Jin W-J., Lee H. K., Jeong E. H., Park W. H., Youk J. H.: Preparation of polymer nanofibers containing silver nanoparticles by using poly( $N$-vinylpyrrolidone $)$. Macromolecular Rapid Communications, 26, 19031907 (2005).

DOI: $\underline{10.1002 / \text { marc. } 200500569}$

[17] Jin W-J., Jeon H. J., Kim J. H., Youk J. H.: A study on the preparation of poly(vinyl alcohol) nanofibers containing silver nanoparticles. Synthetic Metals, 157, 454-459 (2007).

DOI: 10.1016/j.synthmet.2007.05.011
[18] Bai J., Li Y., Li M., Wang S., Zhang C., Yang Q.: Electrospinning method for the preparation of silver chloride nanoparticles in PVP nanofiber. Applied Surface Science, 254, 4520-4523 (2008).

DOI: $10.1016 /$ j.apsusc. 2008.01 .051

[19] Song T., Zhang Y., Zhou T., Lim C. T., Ramakrishna S., Liu B.: Encapsulation of self-assembled FePt magnetic nanoparticles in PCL nanofibers by coaxial electrospinning. Chemical Physics Letters, 415, 317-322 (2005). DOI: $10.1016 /$ j.cplett.2005.09.035

[20] Lu X., Li L., Zhang W., Wang C.: Preparation and characterization of $\mathrm{Ag}_{2} \mathrm{~S}$ nanoparticles embedded in polymer fibre matrices by electrospinning. Nanotechnology, 16, 2233-2237 (2005).

DOI: $10.1088 / 0957-4484 / 16 / 10 / 043$

[21] Abu Bakar N. H. H., Ismail J., Abu Bakar M.: Synthesis and characterization of silver nanoparticles in natural rubber. Materials Chemistry and Physics, 104, 276-283 (2007).

DOI: $10.1016 /$ j.matchemphys.2007.03.015

[22] Fong H., Reneker D. H.: Elastomeric nanofibers of styrene-butadiene-styrene triblock copolymer. Journal of Polymer Science Part B: Polymer Physics, 37, 34883493 (1999).

DOI: 10.1002/(SICI)1099-0488(19991215)37:24<3488 ::AID-POLB9>3.0.CO;2-M

[23] Hao X., Bai C., Huang Y., Bi J., Zhang C., Cai H., Zhang X., Du L.: Preparation of cis-1,4-polyisoprene electrospun microfibers. Macromolecular Materials and Engineering, 295, 305-309 (2010).

DOI: $10.1002 / \mathrm{mame} .200900284$

[24] Pattabi M., Rao K. M., Sainkar S. R., Sastry M.: Structural studies on silver cluster films deposited on softened PVP substrates. Thin Solid Films, 338, 40-45 (1999). DOI: $10.1016 / \mathrm{S} 0040-6090(98) 00970-5$

[25] He S., Yao J., Xie S., Pang S., Gao H.: Investigation of passivated silver nanoparticles. Chemical Physics Letters, 343, 28-32 (2001). DOI: $10.1016 / \mathrm{S} 0009-2614(01) 00566-8$

[26] Decker C., Zahouily K., Decker D., Nguyen T., Thi V.: Performance analysis of acylphosphine oxides in photoinitiated polymerization. Polymer, 42, 7551-7560 (2001).

DOI: 10.1016/S0032-3861(01)00221-X

[27] Decker C., Nguyen T. T. V.: High-speed photocrosslinking of thermoplastic styrene-butadiene elastomers. Journal of Applied Polymer Science, 77, 1902-1912 (2000). DOI: $10.1002 / 1097-4628(20000829) 77: 9<1902:: A I D-$ APP 6>3.0.CO;2-6

[28] Phinyocheep P., Duangthong S.: Ultraviolet-curable liquid natural rubber. Journal of Applied Polymer Science, 78, 1478-1485 (2000).

DOI: $10.1002 / 1097-4628(20001121) 78: 8<1478:: A I D-$ APP30>3.0.CO;2-K 